\title{
Feed Cutting Force Estimation from the Current Measurement with Hybrid Learning
}

\author{
X. $\mathrm{Li}^{1}$, P. K. Venuvinod ${ }^{2}$ and M. K. Chen ${ }^{2}$ \\ ${ }^{1}$ Department of Precision Engineering, Harbin Institute of Technology, Harbin, China; and ${ }^{2}$ Department of Manufacturing Engineering, \\ City University of Hong Kong, Hong Kong
}

\begin{abstract}
It is very important to use reliable and inexpensive sensors to obtain useful information about manufacturing processing, such as cutting force, for monitoring automated machining. In this paper, the feed cutting force is measured using an inexpensive current sensor installed on the a.c. servo motor of a CNC turning centre. The factors that affect a feed drive system are analysed in detail, and a model of the feed drive system for estimating feed cutting force is presented. The feed cutting force is estimated using feed motor current measurement and neuro-fuzzy techniques. Experimental results demonstrate that this method can accurately estimate feed cutting force within an error of $5 \%$.
\end{abstract}

Keywords: Feed cutting force; Motor current; Neuro-fuzzy

\section{Introduction}

It is very important to develop a reliable and inexpensive intelligent monitoring system for cutting processes. A successful monitoring system can effectively maintain machine tools, cutting tools, and workpieces in the cutting processes. Unfortunately, the performance of monitoring systems still lags far behind expectations owing to its high cost/performance ratio [1]. Cutting force is one of important characteristic variables to be monitored in the cutting processes. The research results show that tool breakage, tool wear, and workpiece deflection are strongly related to cutting force [2,3]. Commercial dynamometers have been used to measure cutting force accurately. Though different types of dynamometers are available for different cutting applications, the compliance of machine tools, leading to chatter and dimensional error, and lack of overload protection limit their application owing to high cost [4].

In order to overcome the above disadvantages, a current sensor is used to estimate cutting force in the cutting process. Stein et al. [5] developed a dynamic lumped parameter model

Correspondence and offprint requests to: $\mathrm{Dr} \mathrm{X}$. Li, Department of Manufacturing Engineering, City University of Hong Kong, Tat Chee Avenue, Kowloon, Hong Kong. E-mail: me150001@cityu.edu.hk of a d.c. servo feed drive system, and studied the bandwidth, sensitivity and accuracy of the motor current related to cutting force in the turning processes. Altintas and Dong [6, 7] analysed a machine tool feed drive control system in detail and illustrated the feasibility of using armature current as a measurement sensor for cutting force. Lee et al. [8, 9] presented a real-time tool-breakage detection system for the NC milling process by monitoring cutting force, which was indirectly measured by the feed drive a.c. motor current. Modelling of the feed drive system and calibration with a tool dynamometer showed that the sensitivity of the feed drive motor current was sufficient to characterise the tool breakage. Chang et al. [10] proposed a neural network to construct a model of the spindle cutting system, and estimated the cutting force and detected the chatter of CNC machine tools by measuring the voltage and the current of the spindle motor. Recently, Haber et al. [11] developed an indirect cutting force controller using fuzzy techniques and an a.c. transformer current sensor located in the spindle motor that provides the cutting force signals for the end milling process.

In general, a current sensor is not expensive, is more durable and flexible, and is also very simple to install. Since the feed drive system is a part of the sensing system, the current signal contains information about the condition of the feed drive system. If the current is much higher than the normal current for air cutting, it could indicate a malfunction of a bearing or of lubrication.

In this paper, a model of a feed drive system is established for analysing all the relevant variables. A neuro-fuzzy network is used to estimate feed cutting force based on feed motor current. This feed cutting force measurement, by a current sensor in the feed motor, is set up on the CNC turning centre in our laboratory. The experimental results show that feed cutting force can be accurately estimated using the feed motor current. The experiment indicates a promising future for the suggested method in industrial applications.

\section{Model of the Feed Drive System}

A typical a.c. servo feed system on a CNC lathe consists of the following basic components, as illustrated in Fig. 1: tool, 


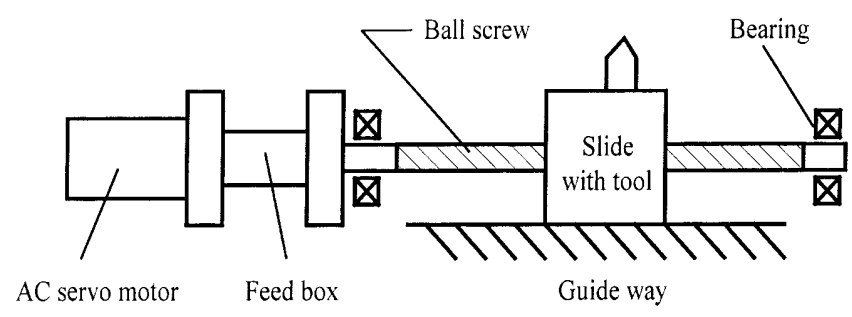

Fig. 1. An a.c. servo feed drive system.

tool post, slide, bearings, ball screw, feed box, feed motor, and lubrication system. The feed drive system can be simplifed, as in Fig. 2. The inertia of the motor armature, feed box, ball screw, and slide are lumped together under the equivalent $J$. Similarly, the viscous damping of the feed box, bearings, ball screw, and slide are lumped together under the equivalent viscous damping, $B$. The dry or Coulomb friction of the slide and other components are also combined as a friction torque, $T_{f}$. Finally, the feed force component is described as a generalised disturbance torque, $T_{c}$, on the feed motor.

For air cutting, the model of the feed drive system is given by

$$
K I_{0}=J \dot{w}+B^{\prime} w+T_{f 0}
$$

where $w$ is the angular velocity of the feed motor

$K$ is the motor constant of the feed motor

$B^{\prime}$ is the equivalent viscous damping for air cutting

$T_{f 0}$ is the dry friction for air cutting

In the cutting process, the viscous damping and friction of the feed drive system change because of the cutting force. The model of the feed drive system can be represented by

$$
K I=J \dot{w}+B w+T_{f}+T_{c}
$$

Combining Eqs (1) and (2),

$$
K \Delta I=\left(B-B^{\prime}\right) w+\left(T_{f}-T_{f 0}\right)+T_{c}
$$

where $\Delta I=I-I_{0}$ is called the cutting current, see Eq. (3). If the effect of viscous damping and friction can be avoided, the effective cutting torque can be estimated by measuring the feed motor current.

In the steady state, $\dot{w}=0$, the monitoring model of the feed drive system can be described as follows:

$$
K I=B w+T_{c}+T_{f}
$$

where $T_{c}$ is the load and $T_{f}$ is the dry friction. It can be expressed as

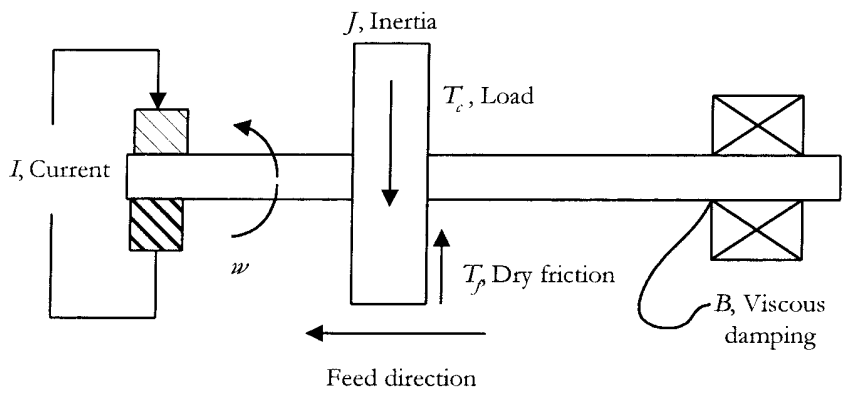

Fig. 2. Model of the feed driver system.
$T_{f}=T_{f 0}+\Delta T_{f}+\Delta T_{v}$

where $T_{f 0}$ is the no load Coulomb friction torque

$\Delta T_{f}$ is the additional Coulomb friction torque increase due to cutting load

$\Delta T_{v}$ is the additional viscous friction torque increase due to cutting load

The actual feed force is related to the disturbance torque as in Eq. (6).

$$
F_{f}=\mu T_{d} / L r
$$

where $F_{f}$ is the feed-cutting force

$\mu$ is the ball screw efficiency

$L r$ is the pitch of the ball screw (length/rotation)

\section{Estimation of Feed Cutting Force}

\subsection{The Air-cutting Current $I_{0}$}

In order to estimate the cutting torque $T_{c}$ by the measured current, the motor current $\Delta I$ caused by the cutting torque has to be separated from the total motor current $I$. First, the current without cutting force $I_{0}$ should be measured at the feed speed. A practical experiment shows that the relationship between the spindle speed and the current consumed is approximately linear, as shown in Fig. 3. In this paper, the linear equation in (7) is used to approximate the linear relationship in Fig. 3.

$$
I_{0}=a v+b
$$

where $I_{0}$ is the current consumed in air cutting, and $v$ is feed speed $\left(\mathrm{mm} \mathrm{min}^{-1}\right)$. The least-squares method can be used to identify the parameters in Eq. (7). The estimated results are shown in Eq. (8).

$$
I_{0}=-0.0007 v+0.3476
$$

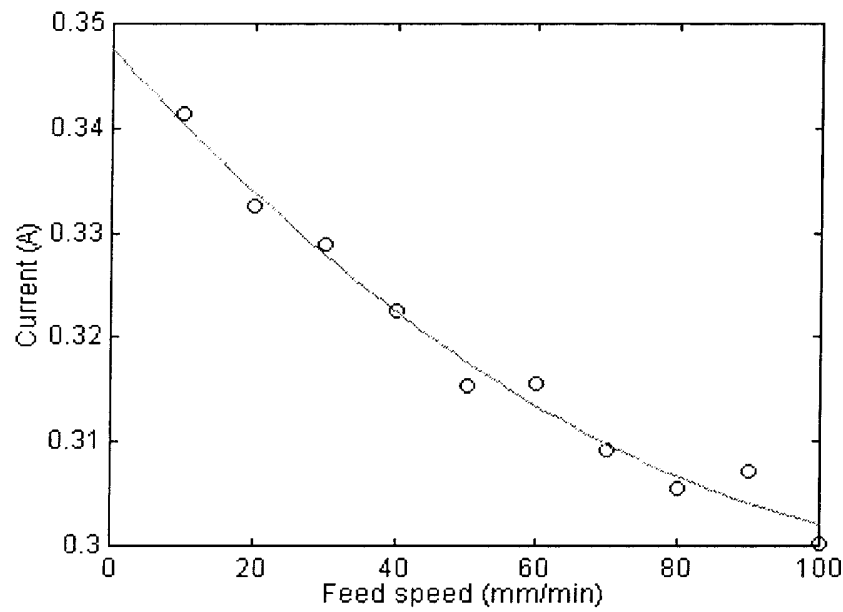

Fig. 3. The relationship between the feed speed and the current in the air cutting. 


\subsection{The Feed Speed and Cutting Current $\Delta I$}

The purpose of the monitoring model is to estimate the feed cutting force using the measured motor current and feed speed. It is known that the current consumed by the feed cutting force is only one part of the total motor current. The current $\left(I_{0}\right)$ consumed by the feed drive system in air cutting can be estimated by Eq. (8). The remaining current $\left(\Delta I=I-I_{0}\right)$, called the cutting current, is due to the cutting force, which is the additional friction caused by the cutting load and damping of the feed drive system $(B)$. Since the additional friction is related to the feed cutting force and damping of the feed drive system that depends on the feed speed, therefore, the estimation of feed cutting force can be expressed as in Eq. (9)

$$
F_{f}=f(\Delta I, v)
$$

It is apparent from that the feed cutting force depends on the cutting current and feed speed. It is essential to understand the relationship of the cutting force and the cutting current and feed speed. The practical measurement in Fig. 4 shows that the feed cutting force increases nonlinearly with the cutting current under steady cutting conditions. On the other hand, the practical measurement in Fig. 5 also shows that the frequency of cutting current signal is linearly related to the feed speed as described in Eq. (10).

$$
v=0.3586 f
$$

Therefore, the feed speed can be estimated using the frequency of the cutting current signal.

\subsection{Feed-Cutting Force $\boldsymbol{F}_{f}$}

In this paper, an adaptive neuro-fuzzy inference system (ANFIS) will be used to estimate the feed cutting force using the cutting current and the feed speed. ANFIS is a four-layer neural network that simulates the working principle of a fuzzy inference system. The weights of the network are tuned using

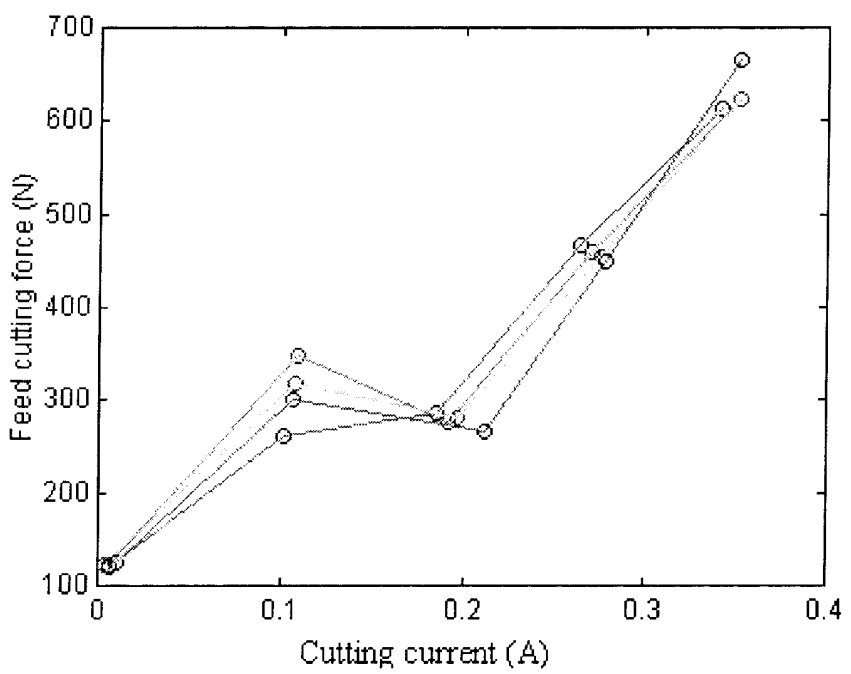

Fig. 4. The relationship between the feed cutting force and the cutting current $(\Delta I)$.

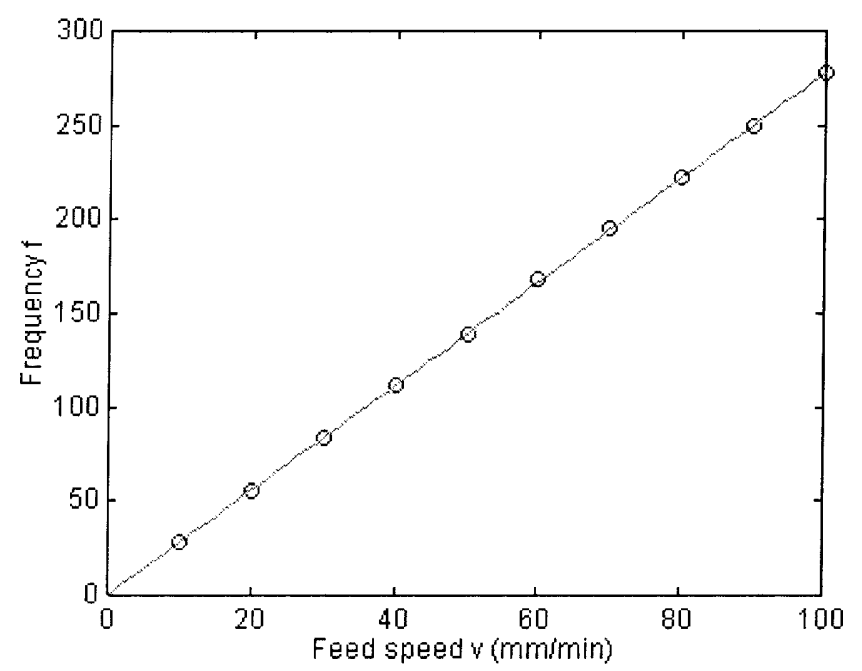

Fig. 5. The linear relationship between the feed speed and the frequency of the current signal.

a back-propagation algorithm based on the collection of inputoutput data. The linguistic nodes in layers one and four represent the input and output linguistic variables, respectively. Nodes in layers two are term nodes acting as membership functions for input variables. Each neuron in the third layer represents one fuzzy rule, with input connections representing preconditions of the rule and the output connection representing consequences of the rules. Initially, all these layers are fully connected, representing all possible rules.

Two feature variables, the remaining current $\Delta I$ and the feed speed $v$, are selected as inputs of the ANFIS. Five membership functions (MFs) are assigned to each linguistic variable. The suggested ANFIS model is shown in Fig. 6 .

The estimation of feed cutting force can be summarised using the operation framework in Fig. 7. The feed motor current is measured using PCB Mounting Hall Effect Current Transducers (stock no. 286-327). The frequency $(f)$ and r.m.s. of the current signal (I) can be obtained via a low-pass $(100 \mathrm{~Hz})$ filter. The feed speed $v$ can be calculated via Eq. (10), and the current consumed $\left(I_{0}\right)$ in air cutting via Eq. (8). Finally, the feed cutting force $F_{f}$ can be estimated using the ANFIS with the feed cutting current $\Delta I$ and feed speed $v$ as two inputs.

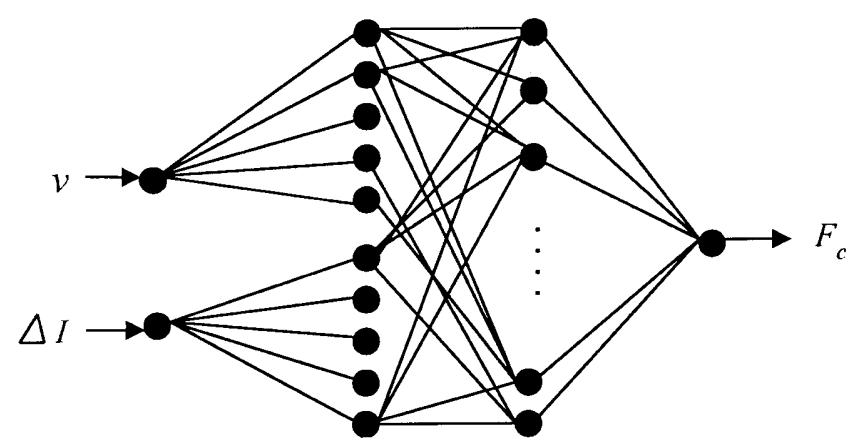

Fig. 6. The ANFIS structure for estimation of the feed cutting force. 


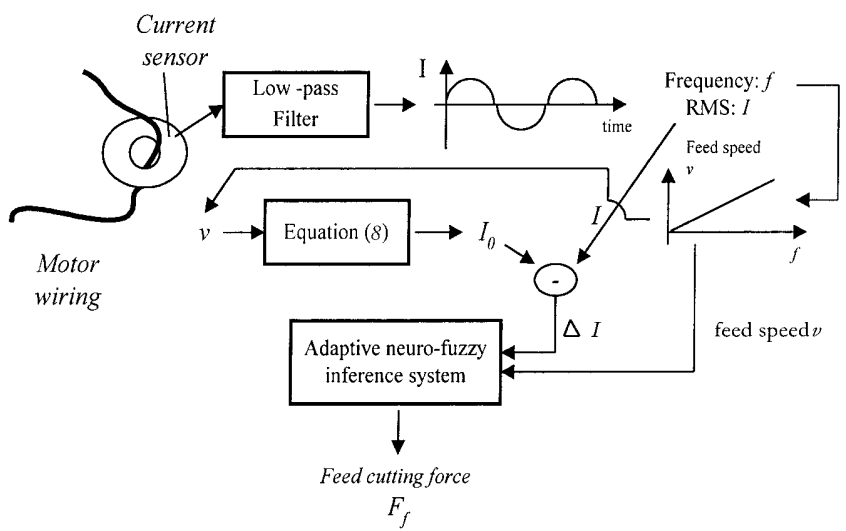

Fig. 7. The operation framework for estimating the feed cutting force.

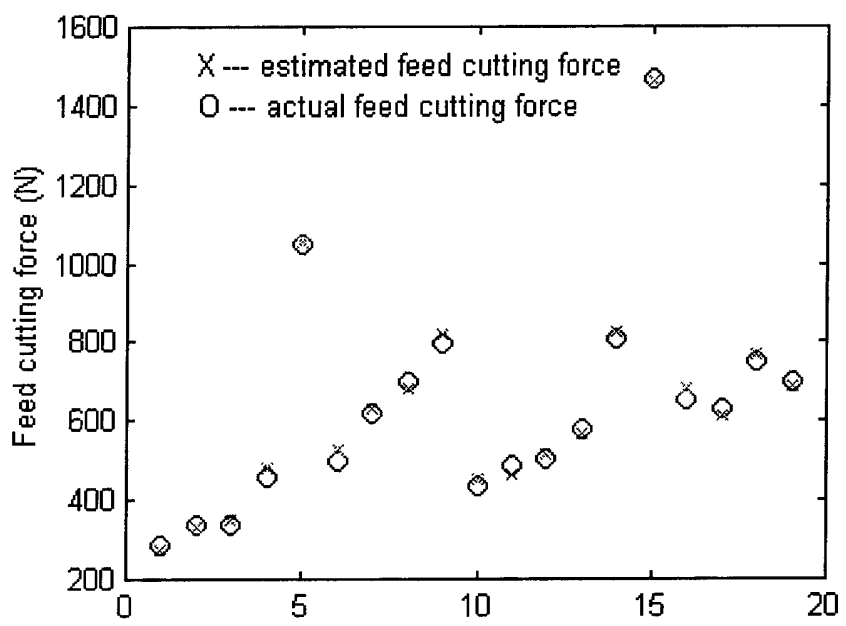

Fig. 8. Comparison of the actual and estimated feed cutting force. The spindle speed is 1000 r.p.m.; feed speed is $10,20,30,40,50 \mathrm{~mm} \mathrm{~min}^{-1}$; depth of cut is $1 \mathrm{~mm}$; workpiece is middle steel; tool radius $r$ is $0.8 \mathrm{~mm}$.

\subsection{Experiment and Discussion}

To compare the estimated results and the actual ones, cutting tests were carried out on the CNC turning centre HITEC TURN 20SII. A Kistler cutting force dynamometer was used to measure the actual cutting force, which was compared with the estimated one obtained via the procedure in Fig. 7. Comparisons were made at different cutting conditions, and are shown in Fig. 8. The error between the actual and the estimated force is within $5 \%$, which validates the accuracy and feasibility of the suggested approach. The advantage of the monitoring system for feed cutting force is that it requires only low-cost sensors (current sensor) and little additional hardware. All that are required are simple data acquisition, filter, data processing and a neural network model.

\section{Summary}

In this paper, the effectiveness of current monitoring has been evaluated as a measure of the feed cutting force on the feed drive system. A monitoring model using an adaptive neurofuzzy network has been developed and experimentally verified on a CNC turning centre. The suggested method is effective and can be easily implemented on a CNC turning centre.

\section{References}

1. Jeffrey L. Stein and Kunsoo Huh, "A design procedure for modelbased monitoring systems: cutting force estimation as a case study", DSC vol. 28/PED vol. 52, Control of Manufacturing Processes, ASME, pp. 45-57, 1991

2. J. Tlusty and G. C. Andrews, "A critical review of sensors for unmanned machining", Annals CIRP 32(2), pp. 611-622, 1983.

3. M. Weck, "Machine diagnostics in automated production", Journal of Manufacturing Systems, 2(2), pp. 101-106 1983.

4. G. Byrne, D. Dornfled, I. Inasaki, G. Ketteler, W. Konig and R. Teti, "Tool condition monitoring (TCM) - The status of research and industrial application", Annals CIRP, 44(2), pp. 541-567, 1995.

5. J. L. Stein, D. Colvin, G. Clever and C.-H. Wang, "Evaluation of d.c. servo machine tool feed drives as force sensors", Journal of Dynamic Systems Measurement and Control, Transactions ASME, 108(4), pp. 279-288, December 1986

6. Y. Altintas and C. L. Dong, "Design and analysis of a modular CNC system for machining control and monitoring", Modeling of Machine Tools: Accuracy, Dynamics, and Control, American Society of Mechanical Engineers, Production Engineering Division (Publication) PED, vol. 45, pp. 199-208, 1990.

7. Y. Altintas, "Prediction of cutting forces and tool breakage in milling from feed drive current measurements", Journal of Engineering for Industry, Transactions ASME, 114(4), pp. 386-392, November 1992.

8. J. M. Lee, D. K. Choi, J. Kim and C. N. Chu, "Real-time tool breakage monitoring for NC milling process", Annals CIRP, 44(1), pp. 59-62, 1995.

9. Tae-Yong Kim and Jongwon Kim, "Adaptive cutting force control for a machining center by using indirect cutting force measurements", International Journal of Machine Tools and Manufacture, 36(8), pp. 925-937, August 1996.

10. Yung-Chih Chang, Kuo-Teng Lee and Hua-Yi Chuang, "Cutting force estimation of spindle motor", Journal of Control Systems and Technology, 3(2), pp. 145-152, June 1995.

11. Rodolfo Elias Haber, Clodeinir R. Peres, Angel Alique, Salvador Ros, Carlos Gonzalez and Jose R. Alique, "Toward intelligent machining: hierarchical fuzzy control for the end milling process", IEEE Transactions on Control Systems Technology, 6(2), pp. 188199, March 1998. 